p-ISSN. 2086-9029

e-ISSN. 2654-5675

Vol. 22 No. 2, HIm. 159-352, Desember 2020

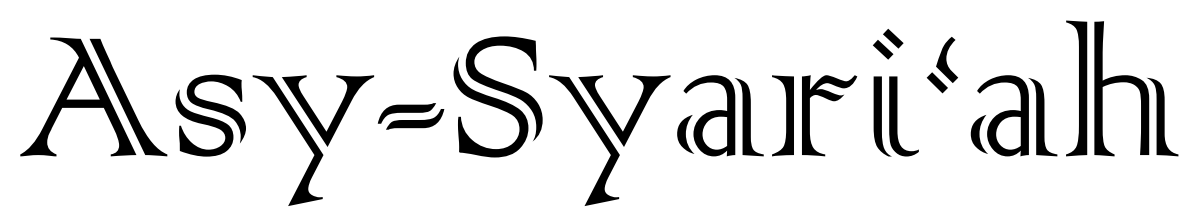

- Implementasi Prinsip Keadilan dalam Hukum Perjanjian Syari'ah

$(159-178)$ Zaenudin Mansyur

- Akad Rahn Tasyjili pada Gadai Tanah Pertanian di Pegadaian Syariah

$(179-196)$ Rahmadi Indra Tektona, Dyah Ochtorina Susanti

- Potensi Sertifikasi Halal dalam Mengahadapi Masyarakat Ekonomi

$(197-218)$ ASEAN

Deviana Yuanitasari, Helitha Noviana Dewi

- Akad Mudharabah sebagai Instrumen Pendanaan dan Pembiayaan di

$(219-236)$ Lembaga Keuangan Syariah

Asep Dadang Hidayat, Moh. Sar'an

- Praktik Rekayasa Dispensing Pump SPBU Persfektif Peraturan

$(237-258)$ Perundang-Undangan dan Hukum Islam

Hazar Kusmayanti, Ratu Chairunissa

- Dinamika Penerapan Akad Syariah dalam Produk Keuangan di Bank

$(259-274)$ Syariah

Jaenudin

- Etika Bisnis Islam pada Perilaku Pemasaran dan Kepuasan Konsumen

$(275-290)$ Wida Ramdania

- Kebijakan Fiskal Islam pada Masa Al-Khilafah Al-Islamiyah

Supriatna, Dedah Jubaedah

- Pelanggaran Prinsip Tanggungjawab Perusahaan Asuransi Investasi Persfektif Perundang-Undangan dan Hukum Ekonomi Syariah

Yoghi Arief Susanto, Yeti Sumiyati

- Identifikasi Kebutuhan Pembiayaan Syariah Peternak Lembu di Deli (337-352) Serdang

Marlya Fatira AK, Anriza Witi Nasution, Tuti Kurnia

FACULTY OF SHARIA AND LAW

STATE ISLAMIC UNIVERSITY SUNAN GUNUNG DJATI BANDUNG-INDONESIA IN COLLABORATION WITH ASOSIASI SARJANA SYARIAH INDONESIA 


\section{Asy-Syari'ah}

Volume 22, Number 2, 2020

\section{EDITOR-IN-CHIEF}

Ine Fauzia

\section{EDITORIAL BOARD}

Sofyan al-Hakim, UIN Sunan Gunung Djati Bandung, Indonesia Deni Kamaludin Yusup, UIN Sunan Gunung Djati Bandung, Indonesia

Meria Utama, Fakultas Hukum Univrsitas Sriwijaya, Indonesia

Dewi Mayaningsih, UIN Sunan Gunung Djati Bandung, Indonesia

Andrey Sujatmiko, Fakultas Hukum Universitas Trisakti, Jakarta, Indonesia

Hetty Hassanah, Universitas Komputer Indonesia, Indonesia

Tarun Ghawana, CDMS, New Delhi, India

Muhammad Hasanuddin, UIN Sunan Gunung Djati Bandung, Indonesia

Syahrul Anwar, UIN Sunan Gunung Djati Bandung, Indonesia

Aden Rosadi, UIN Sunan Gunung Djati Bandung, Indonesia

\section{PEER-REVIEWERS}

S. Salahudin Suyurno, Universiti Teknologi MARA (UiTM) Melaka, Malaysia

Ezani Yaakub, Universiti Teknologi MARA (UiTM) Malaysia, Malaysia

Zezen Zaenal Mutaqin, University of California, Los Angeles, United States

Muhammad Irfan Helmy, IAIN Salatiga, Semarang, Indonesia

Ahmad Ali Nurdin, UIN Sunan Gunung Djati Bandung

Tajul Arifin, UIN Sunan Gunun Djati Bandung, Indonesia

Mohamad Anton Athoillah, UIN Sunan Gunung Djati Bandung, Indonesia

Renny Supriyatni, Universitas Padjadjaran, Indonesia

Ahmad Tholabi Karlie, UIN Syarif Hidayatullah Jakarta, Indonesia

Ija Suntana, UIN Sunan Gunung Djati Bandung, Indonesia

Ahmad Fathonih, UIN Sunan Gunung Djati Bandung, Indonesia

Fauzan Ali Rasyid, UIN Sunan Gunung Djati Bandung, Indonesia

Rahman Syamsuddin, Universitas Islam Negeri Alauddin Makassar, Indonesia

\section{PROOFREADER/DESIGN COVER}

Nanang Sungkawa

\section{LAYOUT EDITOR}

Opik Rozikin

Asy-Syari'ah has been accredited by The Ministry of Education and Cultere, Republic of Indonesia as an academic journal in Sinta 3 (SK Diirjen Penguatan Riset dan Pengembangan Kemristekdikti No. 14/E/KPT/2019), valid for 5 years from Volume 19 No. 1 Tahun 2017 until Volume 23 No. 2 Tahun 2022. 


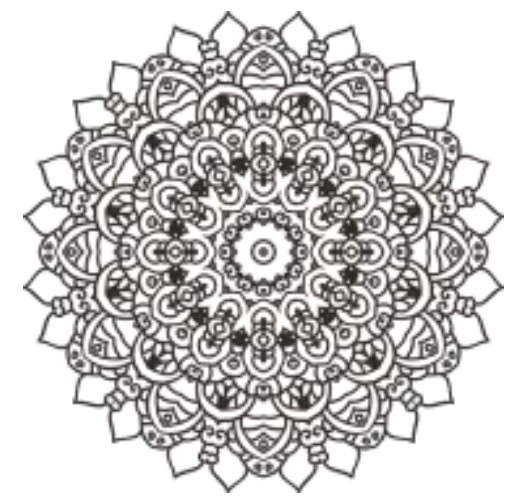

\title{
AKAD RAHN TASJILY PADA GADAI TANAH PERTANIAN DI PEGADAIAN SYARIAH
}

\author{
${ }^{1}$ Rahmadi Indra Tektona, ${ }^{2}$ Dyah Ochtorina Susanti \\ ${ }^{12}$ Universitas Jember \\ E-mail: rahmadiindra@unej.ac.id, dyahochtorina.fh@unej.ac.id
}

\begin{abstract}
This research is motivated by there is an extension of the collateral object, apart from movable, but also immovable assets including farmland which can be applied using the Rahn Tasjily contract. In this regard, in its implementation, it is necessary to analyze whether Rahn Tasjily's contract on pawning of farmland is in accordance with one of the purpose of Islamic law, namely protection of property (hifz al-mal). The purpose of this research is for seeing and understanding the suitability of the Rahn Tasjily pawning farmland with the objectives of Islamic law (hifz al-mal perspective). Research that uses the normative legal research with the statute approach, and conceptual approach, results in Rahn Tasjily pawning farmland provides benefits and protection of property for farmers (rahin), sharia pawnshop (murtahin), and farmland certificate (marhun), and this is certainly in accordance with one of the objectives of Islamic law, namely protection of property (hifz al-mal).
\end{abstract}

Keywords: Rahn Tasjily Contract; Land Pawn; Hifz Al-Mal 
Abstrak: Penelitian ini dilatarbelakangi oleh adanya perluasan objek jaminan yang tidak hanya berupa benda bergerak, tetapi juga benda tidak bergerak termasuk tanah pertanian yang dapat diterapkan menggunakan akad Rahn Tasjily. Terkait demikian, dalam pelaksanaannya, tentu perlu dikaji apakah akad Rahn Tasjily gadai tanah pertanian telah sesuai dengan salah satu tujuan hukum Islam yakni perlindungan terhadap harta (hifz al-mal). Tujuan penelitian ini adalah untuk mengetahui dan pemahami kesesuaian antara akad Rahn Tasjily gadai tanah pertanian dengan tujuan hukum Islam (perspektif hifz al-mal).Penelitian yang menggunakan metode normatif dengan pendekatan perundang-undangan dan pendekatan konseptual ini, menghasilkan temuan bahwa akad Rahn Tasjily gadai tanah pertanian memberikan manfaat dan perlindungan harta terhadap para petani (rahin), pegadaian syariah (murtahin), dan sertifikat tanah pertanian (marhun) itu sendiri, dan hal ini tentu sesuai dengan salah satu tujuan hukum Islam yakni perlindungan terhadap harta (hifz al-mal).

Kata-Kata Kunci: Akad Rahn Tasjily; Gadai Tanah; Hifz Al-Mal 


\section{Pendahuluan}

PT Pegadaian (Persero) adalah salah satu lembaga yang memiliki 3 fungsi yakni: 1) untuk mencegah ijon, rentenir, dan pinjaman tidak wajar lainnya; 2) untuk meningkatkan kesejahteraan rakyat kecil, dan 3) untuk mendukung program pemerintah di bidang ekonomi dan pembangunan nasional. ${ }^{1}$ Terkait demikian, pegadaian juga dijadikan tumpuan untuk memperoleh dana sebagai modal masyarakat yang mekanisme pengajuannya relatif cepat dan sudah sangat familiar bagi masyarakat Indonesia mulai dari kalangan atas hingga bawah, begitu pula dengan masyarakat perkotaan dan pedesaan, terlebih karena prosesnya yang sangat sederhana, efisien, dan efektif sehingga mudah untuk dilaksanakan atau diterapkan oleh seluruh masyarakat termasuk masyarakat pedesaan sesuai dengan kebutuhan saat ini. Berkaitan dengan demikian pula, bagi sebagian orang yang memiliki harta dan bisa dijadikan agunan, pegadaian menjadi pilihan yang tepat, sebab transaksi gadai paling aman, legal dan terlembaga. ${ }^{2}$ Berkenaan dengan hal tersebut, pada perkembangannya dan seiring kebutuhan masyarakat Indonesia yang mayoritas muslim, PT Pegadaian (Persero) kemudian memperluas usahanya tidak hanya dalam lingkup pegadaian konvensional, akan tetapi juga membentuk pegadaian yang berdasar pada nilai-nilai Islam (syariah), dimana selanjutnya pegadaian ini dikenal dengan sebutan Pegadaian syariah.

Pegadaian syariah merupakan sebuah lembaga yang konsep pengoperasiannya merujuk pada sistem administrasi modern berdasarkan asas rasionalitas, efisiensi, dan efektivitas yang disesuaikan dengan nilai-nilai di dalam hukum Islam. ${ }^{3}$ Terkait demikian, perlu dipahami bahwa pada dasarnya pegadaian syariah merupakan bentuk usaha pergadaian, dimana menurut Peraturan Otoritas Jasa Keuangan No. 31/POJK.05/2016 tentang Usaha Pergadaian, usaha pergadaian adalah segala usaha menyangkut pemberian pinjaman dengan jaminan barang bergerak, jasa titipan, jasa taksiran, dan/atau jasa lainnya, termasuk yang diselenggarakan berdasarkan prinsip Syariah. ${ }^{4}$ Pada pelaksanaannya, fungsi operasional pegadaian syariah dijalankan oleh salah satu unit organisasi di bawah binaan Divisi Usaha lain PT. Pegadaian (Persero) yakni kantor-kantor cabang Pegadaian Syariah/Unit Layanan Gadai Syariah (selanjutnya disingkat ULGS), yang didirikan pertama kali pada bulan Januari 2003 di Jakarta bernama ULGS cabang Dewi Sartika, selanjutnya bermunculan ULGS lainnya di tahun yang sama yakni di daerah Surabaya, Makassar, Semarang, Surakarta, dan Yogyakarta. ${ }^{5}$ Berkenaan dengan hal ini, masih di tahun 2003, dimana terdapat 4 (empat) kantor cabang Pegadaian di Aceh yang

\footnotetext{
${ }^{1}$ https://www.pegadaian.co.id/profil/sejarah-perusahaan, diakses pada tanggal 20 Agustus 2020.

${ }^{2}$ Rokhmat Subagiyo, "Tinjauan Syariah Tentang Pegadaian Syariah (Rahn)", Jurnal An-Nisbah, Vol. 1, No. 1, (Oktober 2014), hlm. 162.

${ }^{3}$ Tim Penyusun Laporan Pegadaian. Laporan Tahunan/Annual Report 2009. (Jakarta: Pegadaian, 2009), hlm. 18.

${ }^{4}$ Andri Soemitra, Hukum Ekonomi Syariah Dan Fiqh Muamalah, (Jakarta: Kencana, 2019), hlm. 232.

${ }^{5}$ lbid.
} 
dikonversi menjadi Pegadaian Syariah. ${ }^{6}$ Berkenaan dengan hal tersebut, dalam hal pengelolaan, ULGS sebagai unit bisnis mandiri secara struktural terpisah pengelolaannya dari usaha gadai konvensional, sehingga prosedur atau mekanisme yang ditetapkan juga tidak sama antara ULGS dengan usaha gadai konvensional, mengingat pada prinsipnya, ULGS mengacu atau berpedoman pada nilai-nilai di dalam hukum Islam.

Sehubungan dengan hal di atas, pegadaian syariah sendiri memiliki berbagai produk yang ditawarkan ${ }^{7}$, dan salah satu produk tersebut yaitu pembiayaan syariah. Pembiayaan syariah adalah pembiayaan yang dilakukan dengan tujuan untuk memberikan pertolongan atau bantuan secara sukarela kepada pihak (masyarakat) yang membutuhkan, menghindari dari perbuatan yang mengandung unsur riba, serta perbuatan mendzalimi dan didzalimi. ${ }^{8}$ Salah satu bentuk pembiayaan sebagaimana yang dimaksud yakni pembiayaan Rahn Tasjily Tanah ${ }^{9}$ yakni pembiayaan yang diberikan kepada masyarakat dengan penghasilan tetap, pengusaha mikro/kecil dan petani dengan jaminan sertifikat tanah dan Hak Guna Bangunan (selanjutnya disingkat $H G B$ ) yang didasarkan pada prinsip-prinsip syariah. ${ }^{10}$ Terkait demikian, salah satu faktor adanya jenis pembiayaan Rahn Tasjily Tanah disebabkan karena selama ini masyarakat masih melakukan praktik gadai tanah dengan menggunakan hukum adat. Salah satunya adalah perjanjian berupa appita $^{\prime}$ ala $^{\prime \prime 1}{ }_{1}^{11}$ dimana petani selaku pemilik tanah memberikan sebidang tanahnya kepada seseorang yang mempunyai modal (pemilik modal), sedangkan pemilik modal tersebut selanjutnya menyerahkan sejumlah dana yang dibutuhkan oleh pemilik tanah, dengan kesepakatan bahwa tanah tidak bisa dikembalikan dan dikuasai oleh "pemegang gadai" selama uang gadai belum dikembalikan. ${ }^{12}$ Kesepakatan tersebut tentu merugikan salah satu pihak yakni pemilik tanah, dimana hak untuk mengelola tanah tersebut beralih kepada pemegang gadai, dan ini mengakibatkan pemilik tanah tidak dapat mengelola atau mengerjakan tanahnya sendiri, sehingga petani atau pemilik tanah kesulitan untuk membayar angsuran atau menebus tanah yang dijaminkan tersebut, mengingat tidak ada pemasukan yang

${ }^{6}$ Andri Soemitra, Bank dan Lembaga Kevangan Syariah, (Jakarta: Kencana, 2010), hlm. 393.

${ }^{7}$ Produk pegadaian syariah dibagi menjadi 4 jenis yakni Rahn, Non Rahn, Investasi, dan produk lainnya. Lihat https://pegadaiansyariah.co.id/, diakses pada tanggal 21 Agustus 2020.

${ }^{8}$ Widiana dan Arna Asna Annisa, "Menilik Urgensi Penerapan Pembiayaan Akad Salam pada Bidang Pertanian di Lembaga Keuangan Syariah di Indonesia", Jurnal Muqtasid Vol. 8, No.2, (2017), hlm. 89.

${ }^{9}$ Perlu diketahui pula bahwa pembiayaan Rahn Tasjily ini merupakan produk baru yang ada di dalam sistem ekonomi Indonesia yang memiliki perbedaan dengan gadai konvensional, dimana di dalam gadai konvensional tanah tidak dimasukkan dalam objek atau benda yang dapat digadaikan, sedangkan pada pembiayaan Rahn Tasjily tanah masuk dalam objek atau benda yang digadaikan melalui penggunaan sertifikat tanah dan Hak Guna Bangunan.

${ }^{10}$ https://pegadaiansyariah.co.id/web/produk/rahn-tasjily-tanah, diakses pada tanggal 21 Agustus 2020.

${ }^{11}$ Perjanjian di bawah tangan tersebut lazim disebut appita'gala' (semacam gadai tanah) Kebiasaan masyarakat Sulawesi Selatan, khususnya di Kabupaten Gowa Kecamatan Bontonompo Selatan.

${ }^{12}$ Mustaring dan Sri wahyuni, "Pelaksanaan Gadai Tanah Pertanian Di Desa Tanrara Kecamatan Bontonompo Selatan Kabupaten Gowa", Jurnal Tomalebbi. Vol. 1, No. 3, (Desember, 2014), hlm. 93. 
didapat dan dihasilkan. ${ }^{13}$ Menanggapi hal tersebut, pegadaian syariah kemudian mengeluarkan jenis pembiayaan Rahn TasjilyTanah ini sebagai salah satu produknya.

Berkenaan dengan hal di atas, produk gadai tanah dalam bentuk pembiayaan Rahn Tasjily tanah juga merupakan bentuk atau upaya untuk mendukung kegiatan pembiayaan serta menciptakan praktik gadai tanah yang dapat memberikan kemanfaatan bagi banyak orang, dan mengurangi penderitaan atau kesulitan yang dialami oleh seseorang khususnya petani (pemilik tanah sawah). Berkenaan dengan pelaksanaan akad Rahn Tasjily pada gadai tanah, perlu dipahami bahwa jaminan yang diserahkan kepada penerima jaminan atau yang disebut dengan murtahin hanya sebatas bukti kepemilikan tanah yang dijadikan objek jaminan atau marhun, sementara pengelolaan marhun sendiri ada pada pemberi jaminan atau yang disebut dengan rahin atau yang dalam hukum positif disebut pembebanan hak jaminan dalam bentuk fidusia. Terkait demikian, meskipun telah ditentukan bentuk akad sebagaimana yang diatur dalam Fatwa DSN-MUI, ketentuan dalam fatwa tersebut masih perlu dipertimbangkan dan dikaji, sebab di dalam fatwa ini, terdapat perluasan makna, dimana objek gadai tidak hanya benda bergerak, akan tetapi juga termasuk benda tidak bergerak ${ }_{1}{ }^{14}$ sehingga dikhawatirkan hasil pemanfaatan objek gadai rawan menimbulkan sengketa, karena ketika jaminan yang diserahkan pada murtahin hanya sebatas bukti kepemilikan marhun atau tanah gadai sedangkan pengelolaan marhun tetap pada rahin, maka dimungkinkan terjadi wanprestasi. ${ }^{15} \mathrm{Hal}$ ini dikarenakan saat tanah masih ditanami oleh rahin, hak milik tanaman di atas objek tanah gadai tersebut masih menjadi hak rahin, sehingga pihak murtahin tidak dapat melakukan eksekusi terhadap objek tanah gadai sebagaimana yang dimaksud.

Sehubungan dengan penjelasan di atas, maka diperlukan kajian dan pembahasan yang lebih mendalam mengenai bentuk pembiayaan Rahn Tasjily Tanah ini khususnya berkaitan dengan hasil pemanfaatan objek gadai yang merupakan harta milik rahin yang dijadikan sebagai objek jaminan agar terlindungi dari adanya sengketa yang dimungkinkan dapat muncul kapanpun. Berdasarkan penjelasan tersebut, mengingat pentingnya akad Rahn Tasjily, terdapat satu permasalahan menarik yang akan menjadi pembahasan di dalam di dalam penulisan karya tulis ilmiah ini yaitu apakah akad Rahn Tasjily gadai tanah pertanian di pegadaian syariah telah sesuai tujuan hukum Islam terkait perlindungan terhadap harta? dimana pembahasan terhadap permasalahan tersebut dituangkan di

13 Lastuti Abubakar dan Tri Handayani, "Telaah Yuridis Perkembangan Regulasi dan Usaha Pergadaian Sebagai Pranata Jaminan Kebendaan". Jurnal Bina Mulia Hukum, Vol. 2 No. 1, (September 2017), hlm. 87.

${ }^{14}$ Lihat pengertian Rahn Tasjily pada Ketentuan umum Fatwa DSN-MUI Nomor 68/DSN-MUI/III/2008 tentang Rahn Tasjily yang menyebut istilah "barang" saja, sehingga dalam hal ini kata tersebut dapat diartikan lebih luas.

${ }^{15}$ Sehubungan definisi rahin yaitu pemilik barang gadai, murtahin adalah orang yang mengutangkan yaitu orang yang mengambil barang tersebut serta menahannya, sedangkan barang yang digadaikan disebut rahn. Lihat Mohamad Hilal Nu'man, Implementasi Akad Rahn Tasjily Dalam Lembaga Pembiayaan Syari'ah, Jurnal AKTUALITA, Vol. 1 No. 2, (Desember, 2018), hlm. 6og-610. 
dalam tema besar berjudul "Akad Rahn Tasjily Gadai Tanah Pertanian di Pegadaian Syariah (Perspektif Hifz Al-Mal)".

\section{Metodologi}

Jenis penelitian yang digunakan dalam karya tulis ilmiah ini yakni penelitian hukum normatif atau penelitian hukum doktrinal (doktrinal research). Penelitian hukum normatif adalah penelitian berbasis keputakaan yang bertujuan untuk memberikan eksposisi yang bersifat sistematis mengenai aturan hukum yang mengatur bidang hukum tertentu, menganalisis aturan hukum, bahkan memprediksi perkembangan aturan hukum. ${ }^{16}$ Penelitian hukum normatif juga diartikan sebagai penelitian yang memiliki kecenderungan dalam mencitrakan hukum sebagai dispilin preskriptif, dimana hanya melihat hukum dari sudut pandang norma-normanya saja. ${ }^{17}$ Berkenaan dengan artikel ini, metode penelitian ini digunakan untuk mengkaji dan menganalisis kesesuaian antara akad Rahn Tasjily gadai tanah pertanian di pegadaian syariah dengan salah satu tujuan hukum Islam yakni perlindungan terhadap harta.

Pada penelitian ini pula, penulis akan memaparkan, mengkaji, dan memecahkan isu hukum sebagaimana yang disebut di atas menggunakan pendekatan perundangundangan dan pendekatan konseptual. Berkenaan dengan pendekatan perundangundangan (statute approach) yakni pendekatan yang dilakukan dengan menelaah peraturan perundang-undangan dan regulasi berkaitan dengan isi hukum yang diketengahkan. ${ }^{18}$ Pada karya tulis ilmiah ini, diimplementasikan dengan mengkaji beberapa peraturan perundang-undangan yang mengatur mengenai akad rahn tasjily tanah pertanian yang meliputi: 1) Ketentuan hukum Islam yang bersumber dari Al-Qur'an dan Hadist. 2) Hukum positif di Indonesia yang meliputi: a) UU Nomor 21 Tahun 2008 Tentang Perbankan syariah; b) Peraturan Mahkamah Agung RI No. 2 Tahun 2008 tentang Kompilasi Hukum Ekonomi Syariah; c) Peraturan Otoritas Jasa Keuangan Nomor 31 /POJK.05/2016 Tentang Usaha Pergadaian; d) Fatwa Dewan Syariah Nasional (DSN) Nomor 25/DSN MUI/III/2002 Tentang Rahn; e) Fatwa DSN-MUI Nomor 92/DSN-MUI/IV/2014 tentang Pembiayaan Yang Disertai Rahn; f) Fatwa DSN-MUI Nomor 68/DSN-MUI/III/2008 Tentang Rahn Tasjily.

Sehubungan dengan pendekatan konseptual (conceptual approach), yang digunakan untuk menemukan pandangan-pandangan sarjana hukum dan doktrin yang berkembang di dalam ilmu hukum. ${ }^{19}$ Pada karya ilmiah ini, pendekatan ini dimplementasikan dengan

16 Dyah Ochtorina Susanti dan A'an Efendi, Penelitian Hukum (Legal Research), (Jakarta: Sinar Grafika, 2014), hlm. 11.

${ }^{17}$ Soerjono Soekanto dan Sri Mamudji, Penelitian Hukum Normatif: Suatu Tinjauan Singkat, (Jakarta: Raja Grafindo Persada, 2001), hlm 14.

${ }^{18}$ Ibid., hlm. 10.

${ }^{19}$ Ibid., hlm. 15. 
menganalisis dan mengkaji beberapa pendapat para ahli yang ditemukan dalam bukubuku hukum, jurnal, kamus, arikel, prosiding, maupun referensi lainnya yang membahas mengenai akad rahn tasjily tanah pertanian pada pegadaian syariah, termasuk pembahasan terkait pengertian, mekanisme, dan lain sebagainya.

\section{Akad Rahn Tasjily Pada Gadai Tanah Pertanian Di Pegadaian Syariah}

Perkembangan perekonomian nasional semakin berkembang sangat pesat, dimana hal ini membuka bagi masyarakat khususnya umat Islam untuk mengembangkan inovasi dan kreatifitasnya di bidang ekonomi dengan menghadirkan berbagai bentuk transaksi yang dapat mendukung dan pengembangan perekonomian nasional dan tentunya sesuai dengan Al-Quran, Hadist, serta Peraturan Mahkamah Agung RI No. 2 Tahun 2008 tentang Kompilasi Hukum Ekonomi Syariah Kompilasi Hukum Ekonomi Syariah (selanjutnya disingkat KHES), salah satunya transaksi menggunakan akad Rahn Tasjily.

Sehubungan dengan hal tersebut, sebelum membahas mengenai Rahn Tasjily, penulis akan memberikan pemahaman terlebih dahulu mengenai pengertian Rahn. Menurut Sayyid Sabiq, Rahn adalah menjadikan barang berharga menurut pandangan syara' sebagai jaminan utang. ${ }^{20}$ Barang yang dijadikan jaminan tersebut memiliki nilai ekonomis, dimana pihak yang menahan memperoleh jaminan untuk dapat mengambil kembali seluruh atau sebagian piutangnya. Secara sederhana dapat dijelaskan bahwa Rahn adalah semacam jaminan hutang atau gadai. Pada prinsipnya, praktik Rahn hampir sama dengan dengan praktik gadai secara konvensional, yakni ada barang yang digunakan sebagai jaminan untuk kreditur atau murtahin atas pinjaman yang diberikan kepada debitur atau rahin, sedangkan berkenaan dengan pemeliharaan dan penyimpanan atas marhun pada hakikatnya merupakan kewajiban rahin, selain itu pula besarnya biaya pemeliharaan dan penyimpanan atas marhun tersebut ditentukan berdasarkan akad ijarah, dan akad ijarah inilah yang membedakan antara gadai konvensional dengan rahn. ${ }^{21}$

Berkaitan dengan penjelasan di atas, menurut Al-Quran dan Hadist, Rahn adalah transaksi yang di dalamnya terdapat barang jaminan dan diperbolehkan. Hal ini sebagaimana yang tercantum di dalam O.S. Al-Baqarah Ayat 283 yang terjemahannya sebagai berikut:

"Dan jika kamu dalam perjalanan sedang kamu tidak mendapat seorang penulis, maka hendaklah ada barang jaminan yang dipegang ...". ${ }^{22}$

\footnotetext{
${ }^{20}$ Sayyid Sabiq. Fiqh Sunnah, (Beirut: Daar kitab al-Arabi, 1971), hlm. 153.

${ }^{21}$ Naida Nur Alfisyahri dan Dodik Siswantoro, Praktik dan Karakteristik Gadai Syariah di Indonesia, Jurnal Share, Vol. 1, No. 2, (Juli-Desember, 2012), hlm. 121.

22 Tim Darus Sunah, Al-Qur'an dan Terjemahannya, Edisi Tahun 2002, (Jakarta Timur: CV Darus Sunnah, 2002), hlm. 50 .
} 
Terkait ayat di atas, ada pula beberapa hadist Nabi Muhammad SAW diantaranya diriwayatkan dari Aisyah r.a., yang berkata:

"Sesungguhnya Rasulullah SAW. pernah membeli makanan dengan berhutang dari seorang Yahudi, dan Nabi SAW menggadaikan sebuah baju besi kepadanya." (HR alBukhari dan Muslim) ${ }^{23}$

Ketentuan di atas, menunjukkan bahwa tidak ada larangan adanya barang jaminan dalam transaksi muamalah menurut hukum Islam, asalkan tidak bertentangan dengan prinsip-prinsip syariah atau hukum Islam Terkait demikian, sehubungan dengan barang jaminan di dalam transaksi Rahn memiliki peran sebagai penjamin kepercayaan bahwa rahin akan mengembalikan utangnya (marhun bih) kepada murtahin. Hal ini menunjukkan bahwa di dalam transaksi Rahn, rahin memiliki kewajiban mengembalikan barang jaminan untuk ditahan murtahin sementara waktu, dan dalam hal ini murtahin sebagai pemilik uang boleh meminta jaminan dalam bentuk barang berharga. ${ }^{24}$ Berkenaan dengan hal tersebut, di dalam pelaksanaannya, Rahn diatur di dalam beberapa peraturan perundang-undangan diantaranya pada BAB XIV tentang RAHN tepatnya Pasal 373-408 KHES dan Fatwa DSNMUI 25/DSN-MUI/III/2002 tentang Rahn (selanjutnya disebut Fatwa DSN-MUI 25/DSNMUI/III/2002). Pada KHES, terdapat ketentuan mengenai rukun dan syarat Rahn, dimana rukun dan syarat tersebut menjadi dasar keabsahan transaksi menggunakan akad Rahn yang ketentuannya antara lain: ${ }^{25}$ 1) Rukun akad Rahn terdiri dari murtahin, rahin, marhun, marhun bih, dan akad yang dinyatakan baik secara lisan, tulisan, atau isyarat; 2) Transaksi Rahn dilakukan oleh orang (rahin dan murtahin) yang telah cakap hukum; 3) Barang jaminan (marhun) harus memiliki nilai dan dapat diserahterimakan karena dalam transaksi Rahn, marhun berada dalam penguasaan murtahin; 4) Marhun harus ada ketika akad di lakukan.

Peraturan Rahn selanjutnya yang lebih rinci diatur dalam Fatwa DSN-MUI 25/DSNMUI/II/2002 tentang Rahn, dimana ketentuan tambahan yang dijelaskan dalam Fatwa ini diantaranya: 1) Murtahin diberikan hak untuk mengambil manfaat dari barang yang menjadi marhun atas seijin rahin yakni tanpa mengurangi kualitas dan kuantitas dari barang yang menjadi objek jaminan (marhun), termasuk manfaat dalam hal ekonomi. Pengambilan manfaat tersebut adalah sebagai penggantian perawatan dan bukan sebagai tambahan atas utang rahin kepada murtahin. 2) Rahin menanggung atau membayar biaya perawatan selama penyimpanan jika marhun berada dalam penguasaaan murtahin. 3) Biaya perawatan penyimpanan marhun sebagaimana yang dimaksud diluar utang pokok

${ }^{23}$ Tri Hidayati, et.all. "Mekanisme Penggunaan Jaminan Kebendaan (Rahn Tasjily) Dalam Pembiayan Bank Syariah Di Indonesia dan Malaysia", Jurnal NURANI, Vol. 18, No. 1, (Juni, 2018), hlm. 163-182.

${ }^{24}$ Abdul Rahman Ghazaly, et.all, Fiqh Muamalat, (Jakarta: Kencana Prenadamedia Group, 2015), hlm. 265 .

25 Lihat Pasal 373-376 Peraturan Mahkamah Agung RI Nomor 2 Tahun 2008 tentang Kompilasi Hukum Ekonomi Syariah. 
rahin. 4) Besarnya biaya pemeliharaan dan penyimpanan marhun tidak boleh ditentukan berdasarkan jumlah pinjaman.

Lebih lanjut berkaitan dengan pengertian Rahn Tasjily sendiri yang juga disebut dengan Rahn Rasmi, Rahn Hukmi, atau Rahn Ta'mini, adalah jaminan dalam bentuk barang atas utang, dengan kesepakatan bahwa yang diserahkan kepada penerima jaminan (murtahin) hanya bukti sah kepemilikannya,sedangkan fisik barang jaminan tersebut (marhun) tetap berada dalam penguasaan dan pemanfaatan pemberi jaminan (rahin). ${ }^{26}$ Berdasarkan pengertian tersebut, maka dapat dilihat 2 (dua) unsur di dalam Rahn Tasjily, yakni pertama, Objek Rahn adalah barang, dimana dalam hal ini barang diartikan sebagai segala jenis barang, tanpa membedakan jenis barangnya apakah barang bergerak atau tidak bergerak, barang berwujud atau tidak berwujud; Kedua, marhun yang diserahkan kepada murtahin hanyalah bukti sah kepemilikannya, sedangkan barangnya dalam penguasaan dan pemanfaatan pemberi jaminan (rahin). ${ }^{27}$ Hal ini menunjukkan bahwa di dalam akad Rahn Tasjily, tanah juga dapat dijadikan objek jaminan menggunakan bukti (sertifikat) kepemilikan yang sah. Terlebih sejak dikeluarkannya Fatwa DSN-MUI 68/DSNMUI/III/2008 tentang Rahn Tasjily (selanjutnya disebut Fatwa DSN-MUI 68/DSNMUI/III/2008 tentang Rahn Tasjily) yang didalamnya mengatur mengenai marhun yakni berupa bukti kepemilikan yang ada di dala,m transakasi Rahn di Pegadaian Syariah. ${ }^{28}$ Ketentuan ini merupakan salah satu pembaharuan untuk membuat masyarakat dapat mengajukan pembiayaan dengan marhun yang lebih beragam, salah satunya gadai tanah dalam bentuk sertifikat kepemilikan tanah sebagai jaminannya.

Berkaitan dengan hal di atas, selain dijadikan dasar dalam pelaksanaan gadai tanah, Fatwa DSN-MUI 68/DSN-MUI/III/2008 juga digunakan sebagai dasar hukum produk pegadaian lainnya seperti gadai bukti kepemilikan kendaraan bermotor (BPKB) atau yang disebut ARRUM BPKB. ARRUM (Ar Rahn Untuk Usaha Mikro) sendiri pada Pegadaian Syariah merupakan bentuk pembiayaan yang membantu para pengusaha kecil untuk mendapatkan modal usaha menggunakan jaminan kendaraan, dimana modal usaha tersebut digunakan untuk mengembangkan usahanya. Berkenaan dengan hal itu, di dalam Fatwa DSN-MUI 68/DSN-MUI/II/2008 diuraikan secara jelas tentang marhun yang diserahkan kepada murtahin bukan fisik benda tersebut. Rahin hanya menyerahkan bukti kepemilikan sementara fisik marhun tetap dalam penguasaannya, yang dalam hukum positif dikenal dengan pembebanan hak jaminan dalam bentuk fidusia. ${ }^{29}$ Pada tataran teori, barang yang bisa dijadikan syarat yang terkait dengan barang jaminan (marhun) adalah yang mempunyai nilai ekonomis, harus bisa ditransaksikan dan bisa diserah-

\footnotetext{
${ }^{26}$ Lihat Fatwa Dewan Syariah Nasional No: 68/DSN-MUI/III2008 Tentang Rahn Tasjily.

${ }^{27}$ Lastuti Abubakar dan Tri Handayani, Op. Cit, hlm. 89. Bandingkan dengan Pasal 2 Undang-Undang Nomor 42 Tahun 199 Tentang Fidusia.

${ }^{28}$ Lihat ketentuan terkait pengertian Rahn Tasjily di dalam Fatwa DSN-MUI 68/DSN-MUI/III/2008 tentang Rahn Tasjily.

${ }^{29}$ Rachmadi Usman, Hukum Kebendaan, (Jakarta: Raja Grafindo Persada, 2011), hlm. 283
} 
terimakan ketika akad artinya barang tersebut harus ada pada saat akad berlangsung. Terkait demikian pula, selain ketiga syarat tersebut, adapula syarat lain yang harus dipenuhi yakni barang itu harus berupa harta yang berharga dan dapat dimanfaatkan atau mal al mutaqaqqim, karena apabila manfaat saja, barang tidak bisa dijadikan marhun karena barang itu tidak bisa diserahterimakan ketika akad, selain itu manfaat tidak bisa diketahui nilainya secara jelas. Berkenaan dengan demikian, maka dapat dilihat bahwa marhun merupakan milik mutlak rahin dan tidak terdapat hak orang lain dalam marhun. ${ }^{30}$ Begitu pula dengan gadai tanah, dimana rahin haruslah pemilik sah dari sertifikat tanah yang dijadikan jaminan. Sehubungan dengan hal tersebut, untuk lebih jelasnya, berikut bagan penerapan akad Rahn Tasjily tanah di Pegadaian Syariah.

\section{Bagan 1.}

\section{Akad Rahn Tasjily Tanah di Pegadaian Syariah}

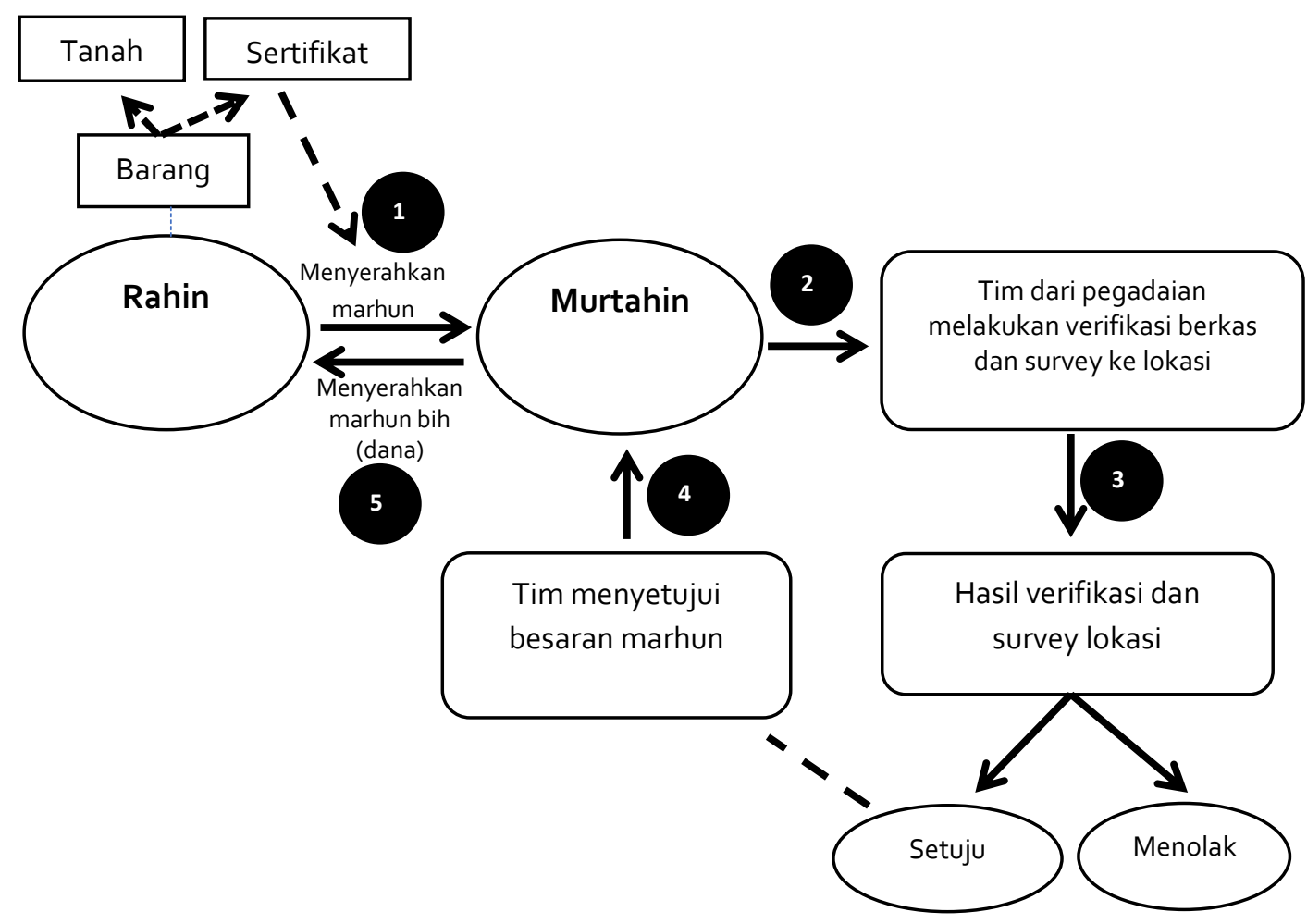

Sumber: catatan pribadi, diolah, 2020.

${ }^{30}$ Abdul Rahman Ghazaly, et.all, Op. Cit., hlm. 267-268. 
Bagan di atas menunjukkan bahwa di dalam pelaksanaan akad Rahn Tasjily tanah di Pegadaian Syariah, ada 5 (lima) tahapan yang harus dilalui, yakni pertama, Rahin datang ke pegadaian syariah untuk mengajukan pembiayaan Rahn Tasjily dengan menyerahkan marhun berupa sertifikat kepemilikan tanah atau HGB (dalam hal ini sertifikat tanah pertanian). Kedua, Murtahin kemudian menerima marhun dan meneruskannya kepada tim pegadaian untuk dilakukan verifikasi berkas dan survey lokasi berdasarkan keterangan di dalam sertifikat tersebut. Ketiga, setelah melakukan verifikasi dan survey lokasi, maka tim akan mengambil keputusan apakah menyetujui besaran marhun atau tidak. Jika setuju, maka tahapan keempat, tim akan menyerahkan hasil persetujuan kepada petugas penerima marhun. Kelima, berdasarkan persetujuan besaran marhun, murtahin selanjutnya menyerahkan marhun bih kepada rahin baik secara tunai maupun transfer. ${ }^{31}$

Berdasarkan penjelasan terkait tahapan pelaksanaan di atas, maka dapat ditemukan adanya 4 (empat) unsur yang terdapat di dalam akad Rahn Tasjily gadai tanah pertanian di Pegadaian Syariah yakni rahin, murtahin, marhun, dan marhun bih, dimana unsur tersebut sama dengan unsur yang terdapat di dalam akad rahn sebagaimana yang dijelaskan sebelumnya. ${ }^{32}$ Terkait demikian, walaupun memiliki unsur yang sama, namun terdapat perbedaan di dalamnya yakni berkenaan dengan marhun. Pada akad Rahn, yang dimaksud marhun yakni berupa barang yang memiliki nilai dan dapat diserahterimakan, artinya barang tersebut bisa berupa barang bergerak, tidak bergerak, berwujud atau tidak berwujud, sedangkan di dalam akad Rahn Tasjily, marhun memiliki pengertian yang lebih spesifik lagi yakni berupa bukti sah kepemilikan atau sertifikat barang, artinya yang menjadi objek jaminan bukan barangnya akan tetapi bukti kepemilikan barang tersebut. Perbedaan lain antara akad Rahn dan akad Rahn Tasjily juga dilihat dari penguasaannya, dimana jika akad Rahn, penguasaan tanah berada di murtahin, sedangkan di dalam akad Rahn Tasjily, penguasaan tanah tetap berada di rahin. Berkaitan dengan kedua perbedaan akad tersebut, menurut hemat Penulis, penerapan akad Rahn Tasjily di dalam gadai tanah pertanian merupakan langkah yang efektif, sebab dengan adanya penguasaan tanah yang tetap berada di pihak rahin, maka rahin dapat mengelola tanah pertanian tesebut, sehingga rahin dapat memperoleh penghasilan yang dapat digunakan untuk menebus sertifikat tanah yang digadaikan tersebut.

Sehubungan dengan penjelasan sebagaimana yang diuraikan di atas, kontruksi pembentukan akad Rahn Tasjily dalam gadai tanah yang berdasar pada ketentuan Fatwa DSN-MUI 68/DSN-MUI/III/2008 sebagaimana yang dijelaskan merupakan wujud imple-

${ }^{31}$ Lihat juga di https://pegadaiansyariah.co.id/web/produk/rahn-tasjily-tanah, diakses pada tanggal 21 Agustus 2020.

32 Lihat Pasal 373 Peraturan Mahkamah Agung RI No. 2 Tahun 2008 tentang Kompilasi Hukum Ekonomi Syariah. 
mentasi dari salah satu tujuan hukum Islam (maqashid syariah) ${ }^{33}$ yakni perlindungan terhadap harta (hifz al-mal), guna melindungi kepentingan dan harta para pihak. Pada tataran terminologi maqashid tradisional, hifz al-mal dikenal dengan arti hukuman bagi pencurian. Perluasan makna hifz al-mal tersebut juga dapat dilihat dari istilah-istilah yang terkait dengan sosiologi ekonomi, misalnya bantuan sosial, pengembangan ekonomi, distribusi uang, masyarakat sejahtera, dan pemerataan ekonomi, dimana hal ini tentu sangat dibutuhkan dalam pengembangan ekonomi di negara-negara mayaroritas muslim. ${ }^{34} \mathrm{Hifz}$ al-mal juga diartikan sebagai perlindungan terhadap harta, dimana menurut ajaran Islam, harta merupakan pemberian Allah kepada manusia, agar dapat mempertahankan hidup dan melangsungkan kehidupannya, dengan cara memperoleh harta kekayaan secara sah dan halal. ${ }^{35}$ Berkenaan dengan hal tersebut, menurut para ahli fiqh harta memiliki kriteria yang terdiri dari unsur nilai ekonomis dan manfaat yang diperoleh dari suatu barang. Nilai ekonomis dan manfaat yang menjadi kriteria harta ditentukan berdasarkan al-'urf $^{6}$, untuk menetapkan apakah suatu barang berstatus al-mal atau bukan sebagaimana ditegaskan oleh as-Sayuti di dalam Asmuni yang mengemukakan bahwa istilah al-mal hanya untuk suatu barang yang memiliki nilai ekonomis, dapat diperjualbelikan, dan dikenakan ganti rugi bagi siapa pun yang merusaknya. ${ }^{37} \mathrm{Hal}$ ini menunjukkan bahwa harta merupakan sesuatu yang penting sehingga harus dipelihara dan dilindungi. Pemeliharaan sebagaimana yang dimaksud tidak hanya ditafsirkan sebagai upaya untuk menjaga harta dari gangguan orang lain, namun juga sebagai hak seseorang untuk mendapatkan harta dengan cara yang halal, bekerjakeras, karena setiap orangmemiliki hak untuk merasakan dan memperoleh harta untuk dapat meningkatkan kualitas hidupnya agar semakin sejahtera.

Lebih lanjut sebagai upaya dalam melindungi harta, Yusuf Hamid al-'Alim dalam Asmuni mengemukakan ada 3 (tiga) prinsip yang dapat dilakukan yaitu prinsip mabda' attaddwul, al-wuduh fi al-amwal, dan al-adalah fi al amwal. ${ }^{38}$ Berkaitan dengan prinsip pertama, mabda' at-tadawwul yaitu prinsip yang bertujuan agar harta berputar dan

33 Berkenaan dengan hal ini, ada 5 (lima) unsur di dalam maqashid syariah yakni perlindungan terhadap agama (hifz al-Din), perlindugan terhadap akal (hifz al-'aql), perlindungan terhadap jiwa (hifz alnafs), perlindungan terhadap harta (hifz al-mal), dan perlindungan terhadap keturunan (hifz al-nasl). Lihat Maftukhatusolikhah, "Mempertimbangkan Tingkat Maqasid asy-Syari'ah dalam Penentuan Anggaran Belanja Pemerintah (Evaluasi terhadap APBN 2008-2013)", Jurnal Intizar, Vol. 21, No. 1, (2015), hlm. 26.

${ }^{34}$ Faizin, "Rekonstruksi Maqâshid Al-Syarî'ah Sebagai Metodologi Tafsir Kontemporer", Jurnal Tajdid, Vol. 22, No. 2, (November 2019), hlm. 179.

${ }^{35}$ Dyah Ochtorina Susanti, "Perjanjian Kawin Sebagai Bentuk Perlindungan Hukum Bagi Pasangan Suami Istri (Perspektif Maqashid Syari'ah)", Jurnal Ulul Albab, Vol. 1, No. 2,( April 2018), hlm. 27.

${ }^{36}$ Al-'urf adalah adat kebiasaan yang berlaku di sebuah daerah dan dijadikan salah satu pertimbangan hukum Islam. Al-'urf juga diartikan sebagai sesuatu yag dikenal manusia dan dijalankan secara biasa, baik berupa perkataan ataupun perbuatan. Lihat M. Noor Harisudin, 'Urf Sebagai Sumber Hukum Islam (Figh) Nusantara, Jurnal AL-FIKR, Vol. 20 No. 1 (2016), hlm. 67.

${ }^{37}$ Asmuni Mth, Perlindungan Terhadap Harta (Perspektif Al-Maqashid Al-Syari 'Ah), Jurnal Millah Vol. V No. 2, (Februari 2006), hlm. 295.

${ }^{38}$ Ibid. 
bergerak di kalangan masyarakat dengan memberlakukan larangan menimbun dan menyimpan harta, larangan melakukan monopoli, melakukan transaksi dengan sistem riba, dan hal-hal lain yang dilarang oleh hukum Islam dan undang-udang. ${ }^{39}$ Kedua, alwuduh fi al-amwal, yaitu agar harta diletakkan pada tempat yang jauh dari konflik sehingga terhindar dari bahaya dan lebih mudah memeliharanya. ${ }^{40}$ Ketiga, al-adalah fi al amwal yakni adil dalam memberlakukan harta, artinya menggunakan harta untuk hal-hal yang terpuji dan bukan untuk dihambur-hamburkan. ${ }^{41}$

Merujuk pada penjelasan hifz al-mal sebagaimana yang diuraikan di atas, maka dapat diketahui dan dipahami bahwa akad Rahn Tasjily gadai tanah pertanian merupakan hal yang sangat penting dan diperlukan untuk memberikan kemaslahatan dan kesejahteraan bagi umat manusia, khususnya bagi para petani yang membutuhkan modal kerja atau biaya untuk mengembangkan usahanya. Berkenaan dengan demikian, dengan adanya Rahn Tasjily, maka masyarakat atau petani (rahin) yang membutuhkan dana atau biaya dapat mengajukan pembiayaan Rahn Tasjily tanah menggunakan sertifikat tanah dan HGB sebagai jaminannya. Rahin dalam hal ini hanya perlu menyerahkan sertifikat kepemilikan tanah tersebut, sedangkan tanah pertanian yang dijadikan sebagai objek jaminan tetap dalam penguasaannya. Hal ini sebagaimana prinsip mabda' at-taddwul, dimana Rahn Tasjily tanah merupakan upaya perlindungan terhadap harta rahin agar harta (tanah pertanian) yang dimiliki petani dapat berputar dan bergerak dengan menghasilkan manfaat berupa pembiayaan dari pegadaian syariah yang bisa dipakai untuk modal kerja atau mengembangkan usahanya. Berkenaan dengan hal tersebut, perlu diketahui pula bahwa pada saat akan mengajukan pembiayaan menggunakan sertifikat tanah pertanian, ada beberapa hal yang harus diperhatikan oleh rahin diantaranya: 1) tanah pertanian yang akan dijadikan objek jaminan (marhun) tidak berada pada struktur tanah yang sulit dijangkau; 2) status tanah bukanlah tanah sengketa atau terblokir; 3) status tanah tidak menjadi jaminan pinjaman/tidak diikat hak tanggungan oleh pihak lain; dan 4) lokasi tanah boleh berbeda dari tempat tinggal rahin selama masih berada dalam naungan satu kantor wilayah yang sama. ${ }^{42} \mathrm{Hal}$ ini dilakukan sebagai bentuk perlindungan harta terhadap objek jaminan (marhun) itu sendiri, guna memperjelas status tanah yang akan dijadikan sebagai objek jaminan agar kedepannya tidak menimbulkan konflik atau sengketa.

Terkait demikian pula, selain memberikan manfaat untuk rahin, adanya marhun berupa sertifikat tanah kepemilikan dalam akad Rahn Tasjily juga memberikan manfaat untuk murtahin, dimana dengan adanya marhun tersebut dapat mencegah terjadinya wanprestasi yang bisa saja dilakukan oleh rahin. Hal ini dikarenakan ada jaminan yang

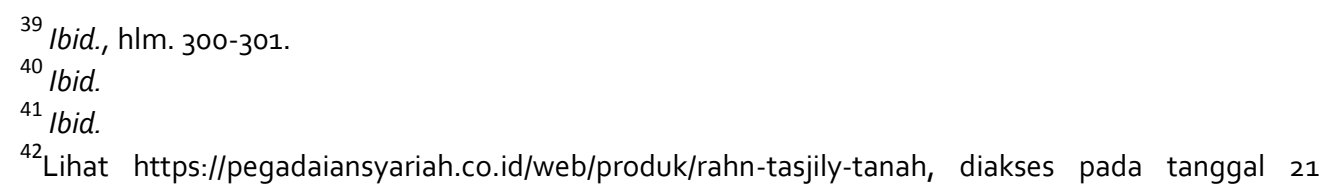
Agustus 2020. 
diserahkan kepada murtahin, sebab apabila rahin menggunakan uang atau harta yang diberikan oleh murtahin untuk hal-hal diluar kesepakatan ataupun murtahin tidak melaksanakan kewajibannya sesuai dengan kesepakatan atau wanprestasi, maka murtahin berhak untuk menjual marhun baik melalui lelang atau dijual kepada pihak lain sesuai dengan prinsip syariah. ${ }^{43}$ Merujuk pada prinsip perlindungan harta, maka dapat dilihat bahwa diserahkannya sertifikat gadai tanah sebagai jaminan kepada murtahin yakni pegadaian syariah telah sesuai dengan prinsip al-wuduh fi al-amwal. Hal ini dikarenakan pegadaian syariah merupakan pilihan yang tepat untuk menyimpan harta rahin (petani) berupa sertifikat tanah, guna menghindari adanya konflik atau sengketa yag disebabkan oleh pelanggaran atau wanprestasi yang bisa saja dilakukan oleh rahin. Berkenaan dengan demikian pula, akan Rahn Tasjily gadai tanah pertanian juga sesuai prinsip al-adalah fi al amwal, dimana harta dari murtahin digunakan untuk hal-hal terpuji, seperti memberikan bantuan atau pembiayaan modal kerja atau usaha untuk para petani.

Hal ini membuktikan bahwa adanya akad Rahn Tasjily gadai tanah pertanian sangat membantu kedua belah pihak baik murtahin maupun rahin untuk menjaga uang atau hartanya masing-masing. Berkaitan dengan demikian, pembentukan akad Rahn Tasjily gadai tanah pertanian juga dapat dilihat dari mekanisme pembayaran yang mudah sehingga dapat diterapkan oleh setiap orang, dan penetapan marhun bih oleh lembaga Pegadaian Syariah sebagai lembaga yang menyelenggarakan kegiatan gadai, bahkan pada ketentuan yang dijelaskan di laman resmi Pegadaian Syariah, telah dijabarkan secara jelas perhitungan uang angsuran pokok beserta biaya perawatan pemeliharaan dari marhun atau objek/barang yang dijaminkan. ${ }^{44} \mathrm{Hal}$ tersebut dapat dijadikan gambaran atau refensi bagi calon nasabah terkait pelaksanaan akad yang akan berlangsung diantara kedua belah pihak. Pada pelaksanaannya, Rahn Tasjily tanah dibagi menjadi 2 (dua) kategori: ${ }^{45}$ 1) Rahn Tasjily Tanah Reguler, yakni pinjaman yang dibayarkan oleh rahin dengan cara angsuran disetor setiap bulan; 2) Rahn Tasjily Tanah Fleksi, yakni pinjaman yang kewajibannya dibayarkan oleh rahin dengan sekali bayar dan secara berkala (3,4, dan 6 bulan).

Sehubungan dengan penjelasan di atas, dapat dilihat bahwa gadai sertifikat tanah yang digagas oleh PT Pegadaian (Persero) merupakan upaya untuk mengembangkan dan memperluas objek gadai sebagai jaminan kebendaan yang hanya dapat dilakukan berdasarkan prinsip syariah melalui penggunaan akad Rahn Tasjily, dimana hal ini tentu sangat membantu masyarakat terutama petani yang membutuhkan dana untuk modal kerja atau pengembangan usahanya. Mengingat akad Rahn Tasjily gadai tanah pertanian ini sangat penting dan bermanfaat untuk banyak orang, maka tentu diperlukan suatu

${ }^{43}$ Lihat ketentuan khusus huruf C Fatwa Dewan Syariah Nasional No: 68/DSN-MUI/III2008 Tentang Rahn Tasjily.

44 Lihat https://pegadaiansyariah.co.id/web/produk/rahn-tasjily-tanah, diakses pada tanggal 21 Agustus 2020.

${ }^{45}$ https://pegadaiansyariah.co.id/web/produk/rahn-tasjily-tanah, diakses pada tanggal 21 Agustus 2020. 
regulasi atau payung hukum guna memberikan perlindungan hukum bagi para pihak, sebab sampai saat ini masih belum ada regulasi yang khusus mengatur mengenai gadai sertifikat tanah. ${ }^{46}$

\section{Simpulan}

Berdasarkan penjelasan sebagaimana yang telah diuraikan pada pembahasan di atas, maka dapat diketahui dan dipahami bahwa akad Rahn Tasjily gadai tanah pertanian di pegadaian syariah telah sesuai dengan salah satu tujuan hukum Islam yakni perlindungan terhadap harta (hifz al-mal) yang meliputi: Pertama, perlindungan terhadap harta petani (rahin) berupa tanah pertanian, dimana tanah pertanian tersebut dapat dimanfaatkan untuk modal kerja atau mengembangkan usahanya melalui pembiayaan Rahn Tasjily tanah guna melindungi harta petani dari penggunaan hal-hal yang tidak baik atau kegiatan yang tidak bermanfaat (menghambur-hamburkan harta), seperti berjudi. Kedua, perlindungan terhadap harta pegadaian syariah (murtahin) berupa uang, dimana dengan adanya akad Rahn Tasjily, uang murtahin dapat diputar dalam bentuk pemberian pembiayaan kepada pertani, dan hal ini tentu mencegah terjadinya penimbunan harta, selain itu harta murtahin juga terlindungi dari adanya pelanggaran kewajiban atau wanprestasi yang dilakukan oleh rahin, mengingat adanya barang yang dijaminkan, membuat rahin berpikir dua untuk tidak melaksanakan kewajibannya (menebus marhun), sebab apabila rahin wanprestasi, maka murtahin akan menjual marhun. Ketiga, perlindungan terhadap objek jaminan berupa sertifikat tanah pertanian (marhun), dimana dengan adanya Rahn Tasjily tanah, mencegah terjadinya syubhat, mengingat objek yang dijaminkan memiliki status yang jelas karena berupa sertifikat kepemilikan tanah pertanian yang sah, sehingga akan terhindar. Sehubungan dengan hal tersebut pula, mengingat sampai saat ini gadai sertifikat tanah belum memiliki payung hukum, maka Penulis memberikan saran kepada Dewan Perwakilan rakyat (DPR) atau pihak pembuat undang-undang untuk menyusun aturan atau regulasi yang mengatur mengenai sertifikat gadai tanah.

\section{Daftar Pustaka}

Abdul Rahman Ghazaly, et.all. Fiqh Muamalat. Jakarta: Kencana Prenadamedia Group. 2015.

Andri Soemitra. Hukum Ekonomi Syariah Dan Fiqh Muamalah. Jakarta: Kencana. 2019.

Bank dan Lembaga Kevangan Syariah. Jakarta: Kencana. 2010

Asmuni Mth. "Perlindungan Terhadap Harta (Perspektif Al-Maqashid Al-Syari 'Ah)", Jurnal Millah Vol. V (2), Februari, (2006). hlm. 295.

${ }^{46}$ Lastuti Abubakar Dan Tri Handayani, hlm. 82. 
Dyah Ochtorina Susanti dan A'an Efendi.Penelitian Hukum (Legal Research). Jakarta: Sinar Grafika. 2014.

Dyah Ochtorina Susanti. "Perjanjian Kawin Sebagai Bentuk Perlindungan Hukum Bagi Pasangan Suami Istri (Perspektif Maqashid Syari'ah)". Jurnal Ulul Albab, Vol. 1 (2), (April 2018): hlm. 27.

Faizin. "Rekonstruksi Maqâshid Al-Syarî’ah Sebagai Metodologi Tafsir Kontemporer". Jurnal Tajdid, Vol. 22 (2), (November, 2019): hlm. 179.

Fatwa Dewan Syariah Nasional No: 68/DSN-MUI/III2008 Tentang Rahn Tasjily.

https://pegadaiansyariah.co.id/web/produk/rahn-tasjily-tanah, diakses pada tanggal 21 Agustus 2020.

https://www.pegadaian.co.id/profil/sejarah-perusahaan, diakses pada tanggal 20 Agustus 2020.

Lastuti Abubakar Dan Tri Handayani. "Telaah Yuridis Perkembangan Regulasi dan Usaha Pergadaian Sebagai Pranata Jaminan Kebendaan". Jurnal Bina Mulia Hukum, Vol. 2 (1), (September, 2019) : hlm. 89.

Luluk Wahyu Roficoh dan Mohammad Ghozali. "Aplikasi Akad Rahn Pada Pegadaian Syariah". Jurnal Masharif al-Syariah: Jurnal Ekonomi dan Perbankan Syariah, Vol 3 (2) (2018): hlm.33.

M. Noor Harisudin. "Urf Sebagai Sumber Hukum Islam (Fiqh) Nusantara". Jurnal AL-FIKR, Vol. 20 No. 1, (2016): hlm. 67.

Maftukhatusolikhah. "Mempertimbangkan Tingkat Maqasid asy-Syari'ah dalam Penentuan Anggaran Belanja Pemerintah (Evaluasi terhadap APBN 2008-2013)". Jurnal Intizar, Vol. 21 (1), (2015): hlm. 26.

Mohamad Hilal Nu'man. "Implementasi Akad Rahn Tasjily Dalam Lembaga Pembiayaan Syari'ah", Jurnal AKTUALITA, Vol. 1 (2), (Desember 2018), hlm. 6o9-610.

Mustaring dan Sri Wahyuni. "Pelaksanaan Gadai Tanah Pertanian Di Desa Tanrara Kecamatan Bontonompo Selatan Kabupaten Gowa". Jurnal Tomalebbi. Vol. 1 (3), (Desember, 2014): hlm. 93.

Naida Nur Alfisyahri dan Dodik Siswantoro. "Praktik dan Karakteristik Gadai Syariah di Indonesia". Jurnal Share, Vol. 1 (2), (Juli-Desember, 2012): hlm. 121.

Peraturan Mahkamah Agung RI No. 2 Tahun 2008 tentang Kompilasi Hukum Ekonomi Syariah.

Peraturan Otoritas Jasa Keuangan No. 31/POJK.05/2016 tentang Usaha Pergadaian.

Rachmadi Usman. Hukum Kebendaan. Jakarta: Raja Grafindo Persada. 2011 
Rahmadi Indra Tektona, Dyah Ochtorina Susanti, Akad Rahn Tasyjili pada Gadai Tanah Pertanian... | 195

Rokhmat Subagiyo. "Tinjauan Syariah Tentang Pegadaian Syariah (Rahn)". Jurnal AnNisbah, Vol. 1 (1), (Oktober, 2014): hlm. 162.

Sayyid Sabiq. Fiqh Sunnah. Beirut: Daar kitab al-Arabi. 1971.

Soerjono Soekanto dan Sri Mamudji. Penelitian Hukum Normatif: Suatu Tinjauan Singkat. Jakarta: Raja Grafindo Persada. 2001.

Tim Darus Sunah. Al-Qur'an dan Terjemahannya, Edisi Tahun 2002. Jakarta Timur: CV Darus Sunnah. 2002.

Tim Penyusun Laporan Pegadaian.Laporan Tahunan/Annual Report 2009. Jakarta: Pegadaian. 2009.

Tri Hidayati, et.all. "Mekanisme Penggunaan Jaminan Kebendaan (Rahn Tasjily) Dalam Pembiayan Bank Syariah Di Indonesia dan Malaysia". Jurnal NURANI, Vol. 18 (1), (2018): hlm. 163-182.

Widiana dan Arna Asna Annisa. "Menilik Urgensi Penerapan Pembiayaan Akad Salam pada Bidang Pertanian di Lembaga Keuangan Syariah di Indonesia", Jurnal Muqtasid, Vol. 8 (2), (2017): hlm. 89. 
196 | Asy-Syari'ah Vol. 22 No.2, Desember 2020

[Halaman ini sengaja dikosongkan] 
Asy-Syari'ah (P-ISSN: 2086-9029 E-ISSN: 2654-5675) is a periodical scientific journal that publishes various results of studies and research, literature review, and other scientific works whose scope covers the field of Islamic law/sharia, law and society in monodisciplinary, interdisciplinary, and multidisciplinary manners. The journal aims to expand and create innovative concepts, theories, paradigms, perspectives and methodologies in the above said scope. The Journal is published twice a year (june and december) by Faculty of Shariah and Law, Sunan Gunung Djati State Islamic University Bandung in collaboration with Asosiasi Sarjana Syariah Indonesia (ASSYI).

\section{EDITORIAL OFFICE:}

Fakultas Syariah dan Hukum UIN Sunan Gunung Djati Bandung J1. Raya A.H. Nasution No. 105 Cibiru Kota Bandung, 40614

Tlp/Fax: +022-7802278 Faks. 022-7802278

Website http://journal.uinsgd.ac.id/index.php/asy-syariah/index

E-mail: Jurnalasy-syariah@uinsgd.ac.id 